\title{
Application of Cystatin C Reduction Ratio to High-Flux Hemodialysis as an Alternative Indicator of the Clearance of Middle Molecules
}

\author{
Joon-Sung Park, Gheun-Ho Kim, Chong Myung Kang, and Chang Hwa Lee \\ Department of Internal Medicine, Hanyang University College of Medicine, Seoul, Korea
}

Background/Aims: Although high-flux (HF) dialyzers with enhanced membrane permeability are widely used in current hemodialysis (HD) practice, urea kinetic modeling is still being applied to indicate the adequacy of both low-flux (LF) and HF HD. In comparison with urea (molecular weight, $60 \mathrm{Da})$ and $\beta_{2}$-microglobulin ( $\beta_{2} \mathrm{MG}, 12$ $\mathrm{kDa})$, cystatin $\mathrm{C}(\mathrm{CyC}, 13 \mathrm{kDa})$ is a larger molecule that has attractive features as a marker for assessing solute clearance. We postulated that $\mathrm{CyC}$ might be an alternative for indicating the clearance of middle molecules (MMs), especially with HF HD.

Methods: Eighty-nine patients were divided into LF and HF groups. Using single pool urea kinetic modeling, the urea reduction ratio (URR) and equilibrated $\mathrm{Kt} / \mathrm{Vurea}$ (eKt/Vurea) were calculated. The serum CyC concentrations were measured using particle-enhanced immunonephelometry. As indices of the middle molecular clearance, the reduction ratios of $\beta_{2} \mathrm{MG}$ and $\mathrm{CyC}$ were calculated.

Results: The $\beta_{2} M G$ reduction ratio ( $\left.\beta_{2} M G R R\right)$ and CyC reduction ratio (CyCRR) were higher in the HF group compared to the LF group. However, the URR and eKt/Vurea did not differ between the two groups. The CyCRR was significantly correlated with the eKt/Vurea and $\beta_{2} \operatorname{MGRR}(r=0.47$ and 0.69 , respectively, both $p<0.0001)$.

Conclusions: Compared to the LF dialyzer, the HF dialyzer removed CyC and $\beta_{2} M G$ more efficiently. Unlike the $\beta_{2} M G R R$, the CyCRR was correlated with the eKt/Vurea and $\beta_{2} M G R R$. This study suggests a role for the CyCRR as an alternative indicator of the removal of MMs. (Korean J Intern Med 2010;25:77-81)

Keywords: Dialysis; beta 2-Microglobulin; Cystatin C

\section{INTRODUCTION}

The uremic syndrome is attributable to the progressive retention of a large number of compounds, which are called uremic retention solutes or uremic toxins, when they interact negatively with physiologic function. They include not only small plasma solutes, but also proteinbound solutes and middle molecules (MMs) [1]. Their retention may lead to dialysis morbidity and mortality, which are poorly resolved with conventional hemodialysis (HD).

Since the beginning of the 1980 , urea kinetic modeling has been applied to quantify the removal of small solutes by conventional HD. In current practice, high-flux (HF) dialyzers may allow more efficient removal of larger molecules, which is expected to reduce the risk of HDrelated morbidity and mortality substantially. Conversely, no consensus exists concerning the best dialysis dose index and method for calculating it $[2,3]$.

Of the MMs, cystatin $\mathrm{C}$ (CyC, molecular weight [MW], $13 \mathrm{kDa}$ ) is freely filtered at the level of the glomerulus and virtually all is reabsorbed and metabolized by proximal tubular cells [4-7]. Due to its molecular characteristics, numerous studies have shown that $\mathrm{CyC}$ is the most 
Table 1. Demographic characteristics

\begin{tabular}{|c|c|c|c|}
\hline & $\begin{array}{l}\text { Low-flux hemodialysis } \\
\qquad(\mathrm{n}=37)\end{array}$ & $\begin{array}{l}\text { High-flux hemodialysis } \\
\qquad(\mathrm{n}=52)\end{array}$ & $p$ value \\
\hline Age, yr & $56.1 \pm 12.2$ & $54.0 \pm 12.4$ & NS \\
\hline Male gender & $17(46.0)$ & $25(48.1)$ & NS \\
\hline Diabetes mellitus & $14(37.8)$ & $15(28.9)$ & NS \\
\hline Duration of hemodialysis, mon & $71.6 \pm 79.9$ & $112.7 \pm 188.6$ & NS \\
\hline Body mass index, $\mathrm{kg} / \mathrm{m}^{2}$ & $20.9 \pm 3.0$ & $20.7 \pm 2.8$ & NS \\
\hline Hemoglobin, g/dL & $9.7 \pm 1.5$ & $9.8 \pm 1.1$ & NS \\
\hline C-reactive protein & $0.38 \pm 0.44$ & $0.17 \pm 0.24$ & 0.0039 \\
\hline
\end{tabular}

Values are presented as mean \pm SD for continuous variables and number (\%) for nominal variables.

NS, not significant.

Table 2. Clearance according to dialyzer

\begin{tabular}{|c|c|c|c|}
\hline & Low-flux hemodialysis & High-flux hemodialysis & $p$ value \\
\hline Urea reduction ratio, \% & $67.8 \pm 13.0$ & $70.3 \pm 6.7$ & NS \\
\hline $\mathrm{eKt} / \mathrm{Vurea}_{\text {u }}$ & $1.19 \pm 0.32$ & $1.29 \pm 0.23$ & NS \\
\hline$\beta_{2} \mathrm{MG}$ reduction ratio, $\%$ & $7.0 \pm 25.0$ & $42.5 \pm 14.9$ & $<0.0001$ \\
\hline $\mathrm{Kt} / \mathrm{V}_{\beta_{2} \mathrm{MG}}$ & $0.24 \pm 0.38$ & $0.84 \pm 0.29$ & $<0.0001$ \\
\hline CyC reduction ratio, $\%$ & $11.5 \pm 16.2$ & $42.4 \pm 6.3$ & $<0.0001$ \\
\hline
\end{tabular}

Values are presented as the mean $\pm \mathrm{SD}$.

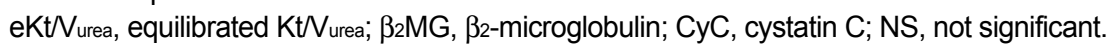

promising endogenous marker of the glomerular filtration rate [8]. In addition, several studies have suggested that $\mathrm{CyC}$ is useful as a marker of HD toxin removal, since the plasma CyC has attractive features as a representative MM [9,10].

For these reasons, we hypothesized that the $\mathrm{CyC}$ reduction ratio (CyCRR) might reflect the removal of MMs and could be applied to the dialysis dose index in $\mathrm{HD}$, and we designed this single-center, case-control study to examine our hypotheses.

\section{METHODS}

\section{Patients}

All of the patients underwent maintenance HD at Hanyang University Hospital three times per week. Previously, all 89 patients had chosen low-flux (LF) HD as the dialysis modality. The dialysis modality was chosen according to patient preference, and the dialyzers used were F6HPS for LF and F6oS for HF (Fresenius Medical Care, Bad Homburg, Germany). We assumed that no residual renal function was preserved in any patient. Patients were excluded if they were medically unstable, younger than 18 years of age, or mentally disabled.

\section{Measurements}

All blood samples were taken before and after the second HD session of the week, according to the guidelines for HD adequacy [11]. Blood samples were collected in tubes without additional anticoagulant and allowed to stand at room temperature for 30 to 60 minutes. Then, the samples were centrifuged to collect serum, which was stored at $70^{\circ} \mathrm{C}$ until assayed. Urea nitrogen was measured using a Hitachi 7600 series automatic biochemical analyzer (Hitachi High-Technologies, Tokyo, Japan). Serum $\beta 2-$ microglobulin ( $\beta 2 \mathrm{MG}, \mathrm{MW}, 12 \mathrm{kDa}$ ) concentrations were measured using a chemiluminescent enzyme immunoassay (DPC IMMUNLITE 2000, Diagnostic Products, Los Angeles, CA, USA). CyC was assayed using particleenhanced immunonephelometry (BN II nephelometer, Dade Behring, Reuil Malmaison, France). All other measurements were made using routine laboratory methods.

We calculated the reduction ratios of solutes for urea, $\beta 2 \mathrm{MG}$, and CyC during the treatment. The single-pool urea Kt/V (spKt/Vurea) values were calculated using the second-generation natural logarithmic formula described by Daugirdas [12], and we transformed the spKt/Vurea to 
Table 3. Correlation coefficient between clearance

\begin{tabular}{lclll}
\hline & Urea reduction ratio & eKt $/ \mathrm{Vurea}$ & $\beta_{2 \mathrm{MG} \text { reduction ratio }}$ & $\mathrm{Kt} / \mathrm{V}_{\beta 2 \mathrm{MG}}$ \\
\hline$\beta_{2} \mathrm{MG}$ reduction ratio & $0.2508^{\mathrm{a}}$ & $0.3375^{\mathrm{b}}$ & & \\
$\mathrm{Kt} / \mathrm{V}_{\beta_{2} \mathrm{MG}}$ & 0.2227 & 0.2904 & $0.6920^{\mathrm{b}}$ & $0.6861^{\mathrm{b}}$ \\
$\mathrm{CyC}$ reduction ratio & $0.3962^{\mathrm{b}}$ & $0.4692^{\mathrm{b}}$ & & \\
\hline
\end{tabular}

eKt/Vurea, equilibrated Kt/Vurea; $\beta_{2} \mathrm{MG}, \beta_{2}$-microglobulin; CyC, cystatin C.

a $p<0.05$.

${ }^{\mathrm{b}} p<0.01$.

the equilibrated Kt/Vurea (eKt/Vurea) [13].

The clearance of $\beta_{2} \mathrm{MG}\left(\mathrm{K}_{\beta 2 \mathrm{MG}}\right)$ was determined using the formula described by Cheung et al. [14] and then the $\mathrm{Kt} / \mathrm{V}_{\beta 2} 2 \mathrm{MG}$ was calculated by multiplying the $\mathrm{K}_{32 \mathrm{MG}}$ by the treatment time and dividing the result by the post-dialysis volume.

\section{Statistical analysis}

Baseline characteristics are presented as the mean $\pm \mathrm{SD}$ or as the proportions of patients in the groups. The Shapiro-Wilk test was used to test for normality. Continuous variables were compared using the Mann-Whitney $U$ test. The chi-square test with Fisher's exact test was applied to evaluate associations between nominal variables. The Spearman correlation coefficient was used to study correlations between variables. All $p$ values were analyzed using two-sided tests, and $p$ values $<0.05$ were considered statistically significant. All analyses were performed with SAS version 9.1 (SAS Institute, Cary, NC, USA).

\section{RESULTS}

Eighty-nine patients were included and divided into LF $(\mathrm{n}=37)$ and HF $(\mathrm{n}=52)$ groups. Dialysis was performed for $4.0 \pm 0.2 \mathrm{hr} / \mathrm{session}$ with blood flow rates of $237 \pm 23$ $\mathrm{mL} / \mathrm{min}$ and dialysate flow rates of $500 \mathrm{~mL} / \mathrm{min}$ using bicarbonate dialysate. The dialysis machine, water treatment circuit, and tank were sterilized regularly.

No differences existed between the two groups with respect to the demographic characteristics and the cause of end-stage renal disease (Table 1 ). The C-reactive protein was higher in the LF HD group ( $p=0.0039$ ), but was not correlated with the indices of solute removal in this study (data not shown). The etiology of renal failure in the patients included diabetes mellitus $(\mathrm{n}=29,32.6 \%)$, hypertension ( $\mathrm{n}=18,20.2 \%$ ), chronic glomerulonephritis ( $n=12,13.5 \%)$, and shrunken kidneys of unknown etiology
( $\mathrm{n}=23,25.8 \%)$.

The eKt/Vurea in the LF and HF HD groups was $1.19 \pm$ 0.32 and $1.29 \pm 0.23$, respectively. No differences were observed in the urea reduction ratio (URR) and eKt/Vurea between the two groups (Table 2). However, $\beta 2 \mathrm{MG}$ and CyC were removed more efficiently by the HF dialyzer ( $p$ $<0.0001)$.

When all patients were considered, the CyCRR was strongly correlated with the $\beta 2 \mathrm{MG}$ reduction ratio ( $\beta 2 M G R R)$ and $\mathrm{Kt} / \mathrm{V}_{\text {B2MG }}$ and weakly correlated with the URR and eKt/Vurea (Table 3). The pre-dialysis CyC and $\beta 2 \mathrm{MG}$ levels, and their reduction ratios were not correlated with the albumin, normalized protein catabolic rate, or Creactive protein (data not shown).

\section{DISCUSSION}

We assessed the performance of the CyCRR as representative of the clearance of MMs. As in previous reports $[14,15]$, no difference existed between the two groups in terms of the URR and eKt/Vurea. In addition, the more efficient removal of $\beta 2 \mathrm{MG}$ in the HF HD group concurred with a past study [14]. However, we found that the CyCRR had a prominent relationship with the $\beta 2$ MGRR and $\mathrm{Kt} / \mathrm{V}_{\beta_{2} \mathrm{MG}}$ in $\mathrm{HD}$.

Most of the small water-soluble uremic retention compounds and MMs that have been shown to exert biologic action have an intradialytic kinetic behavior that is indisputably different from that of urea [16], and their retention is poorly resolved with conventional HD. Therefore, many past studies have emphasized that the removal of small water-soluble uremic retention compounds and MMs using a HF dialyzer may ensure excellent dialysis quality, influence the clinical outcomes of patients in several areas, and reduce the acute and longterm HD-related complications [1,17-20]. These may be particularly important in patients with no residual renal 
function, who depend completely on dialysis efficiency. Assessing dialysis adequacy using several molecules simultaneously is suitable to reflect small solute and MM clearance [21].

$\beta 2 M G$ had been accepted as representative of MMs and is widely recognized as a key component in the development of dialysis-associated amyloidosis [22]. Several studies demonstrated that the use of a HF dialyzer might improve the clearance of $\beta 2 \mathrm{MG}$ and decrease pre-dialysis plasma levels [23,24]. They expected that HD with a HF dialyzer could reduce the development of amyloidosis and improve patient quality of life. Given the fluctuating $\beta 2 \mathrm{MG}$ production rate, nonrenal route of elimination, other factors influencing its bloodstream delivery, and intercompartmental transport, $\beta 2 \mathrm{MG}$ removal is recognized as not being a good indicator $[25,26]$.

After exploring the interrelationship of low-molecularweight proteins with the glomerular filtration rate, an increasing serum $\mathrm{CyC}$ level was found to be related to decreasing renal function and to be associated with some cerebral amyloid angiopathies, tumor progression, and inflammatory processes [27-30]. In addition, some attractive features as a representative MM made us assess the performance of $\mathrm{CyC}$ during $\mathrm{HD}$ : because CyC should be distributed strictly in extracellular fluid, various kinetic models are not required to describe its kinetics during $\mathrm{HD}$; its production rate is relatively constant or minimally variable; CyC is a free-circulating, unbounded form, and its elimination from the circulation is almost entirely through glomerular filtration; and $\mathrm{CyC}$ may be a prognostic biomarker of the risk of death and cardiovascular disease [31,32].

Starting from the hypothesis that the clearance of CyC is representative of the removal of MMs and its reduction ratio is a useful marker of toxin removal in HD, we performed this study to compare the CyCRR with the most widely used methods for measuring HD adequacy. Since CyC has several merits as a representative MM - it is similar to $\beta 2 \mathrm{MG}$ in molecular weight and clearance during $\mathrm{HD}$, and its reduction ratio has some relationship with the URR and eKt/Vurea - the CyCRR should be useful as an alternative to the $\beta_{2} \mathrm{MGRR}$ and $\mathrm{Kt} / \mathrm{V}_{32 \mathrm{MG}}$ for estimating the dialysis clearance of MMs. However, further studies with larger sample sizes should be performed to draw a firm conclusion as to whether the CyCRR is useful indicator of the clearance of MMs.

\section{Conflict of interest}

No potential conflict of interest relevant to this article was reported.

\section{REFERENCES}

1. Vanholder R, De Smet R, Glorieux G, et al. Review on uremic toxins: classification, concentration, and interindividual variability. Kidney Int 2003;63:1934-1943.

2. Prado M, Roa LM, Palma A, Milan JA. Double target comparison of blood-side methods for measuring the hemodialysis dose. Kidney Int 2005;68:2863-2876.

3. Vienken J, Bowry S. Quo vadis dialysis membrane? Artif Organs 2002;26:152-159.

4. Mussap M, Plebani M. Biochemistry and clinical role of human cystatin C. Crit Rev Clin Lab Sci 2004;41:467-550.

5. Rule AD, Bergstralh EJ, Slezak JM, Bergert J, Larson TS. Glomerular filtration rate estimated by cystatin $\mathrm{C}$ among different clinical presentations. Kidney Int 2006;69:399-405.

6. Shlipak MG, Praught ML, Sarnak MJ. Update on cystatin C: new insights into the importance of mild kidney dysfunction. Curr Opin Nephrol Hypertens 2006;15:270-275.

7. Knight EL, Verhave JC, Spiegelman D, et al. Factors influencing serum cystatin $\mathrm{C}$ levels other than renal function and the impact on renal function measurement. Kidney Int 2004;65:1416-1421.

8. Mojiminiyi OA, Abdella N. Evaluation of cystatin C and beta-2 microglobulin as markers of renal function in patients with type 2 diabetes mellitus. J Diabetes Complications 2003;17:160-168.

9. Campo A, Lanfranco G, Gramaglia L, Goia F, Cottino R, Giusto V. Could plasma cystatin $\mathrm{C}$ be useful as a marker of hemodialysis low molecular weight proteins removal? Nephron Clin Pract 2004;98:c79-c82.

10. Thysell H, Grubb A, Lindholm T, Ljunggren L, Martensson L. Cystain C: a new marker of biocompatibility or a good marker for the redistribution of LMW proteins during hemodialysis? ASAIO Trans 1988;34:202-204.

11. Hemodialysis Adequacy 2006 Work Group. Clinical practice guidelines for hemodialysis adequacy, update 2006. Am J Kidney Dis 2006;48 Suppl 1:S2-S9o.

12. Daugirdas JT. Second generation logarithmic estimates of singlepool variable volume Kt/V: an analysis of error. J Am Soc Nephrol 1993;4:1205-1213.

13. Diaz-Buxo JA, Loredo JP. Standard Kt/V: comparison of calculation methods. Artif Organs 2006;30:178-185.

14. Cheung AK, Levin NW, Greene T, et al. Effects of high-flux hemodialysis on clinical outcomes: results of the HEMO study. $\mathrm{J}$ Am Soc Nephrol 2003;14:3251-3263.

15. Ayli D, Ayli M, Azak A, et al. The effect of high-flux hemodialysis on renal anemia. J Nephrol 2004;17:701-706.

16. Vanholder R, Glorieux G, De Smet R, Lameire N. New insights in 
uremic toxins. Kidney Int Suppl 2003;(84):S6-S10.

17. Basile C. The effect of convection on the nutritional status of haemodialysis patients. Nephrol Dial Transplant 2003;18 Suppl 7:vii46- vii49.

18. Leypoldt JK, Cheung AK. Removal of high-molecular-weight solutes during high-efficiency and high-flux haemodialysis. Nephrol Dial Transplant 1996;11:329-335.

19. Clark WR, Gao D. Determinants of uraemic toxin removal. Nephrol Dial Transplant 2002;17 Suppl 3:30-34.

20. Locatelli F, Manzoni C, Di Filippo S. The importance of convective transport. Kidney Int Suppl 2002;(80):115-120.

21. Lindsay RM, Henderson LW. Adequacy of dialysis. Kidney Int Suppl 1988;24:S92-S99.

22. Evenepoel P, Bammens B, Verbeke K, Vanrenterghem Y. Superior dialytic clearance of beta(2)-microglobulin and p-cresol by highflux hemodialysis as compared to peritoneal dialysis. Kidney Int 2006;70:794-799.

23. Ayli M, Ayli D, Azak A, et al. The effect of high-flux hemodialysis on dialysis-associated amyloidosis. Ren Fail 2005;27:31-34.

24. Locatelli F, Andrulli S, Pecchini F, et al. Effect of high-flux dialysis on the anaemia of haemodialysis patients. Nephrol Dial Transplant 2000;15:1399-1409.

25. Leypoldt JK, Cheung AK, Deeter RB. Rebound kinetics of beta2- microglobulin after hemodialysis. Kidney Int 1999;56:1571-1577. 26. Ward RA, Greene T, Hartmann B, Samtleben W. Resistance to intercompartmental mass transfer limits beta2-microglobulin removal by post-dilution hemodiafiltration. Kidney Int 2006;69: 1431-1437.

27. Newman DJ. Cystatin C. Ann Clin Biochem 2002;39(Pt 2):89104.

28. Levy E, Jaskolski M, Grubb A. The role of cystatin C in cerebral amyloid angiopathy and stroke: cell biology and animal models. Brain Pathol 2006;16:60-70.

29. Reed CH. Diagnostic applications of cystatin C. Br J Biomed Sci 2000;57:323-329.

30. Revesz T, Ghiso J, Lashley T, et al. Cerebral amyloid angiopathies: a pathologic, biochemical, and genetic view. J Neuropathol Exp Neurol 2003;62:885-898.

31. Ix JH, Shlipak MG, Chertow GM, Whooley MA. Association of cystatin $\mathrm{C}$ with mortality, cardiovascular events, and incident heart failure among persons with coronary heart disease: data from the Heart and Soul Study. Circulation 2007;115:173-179.

32. Shlipak MG, Katz R, Sarnak MJ, et al. Cystatin C and prognosis for cardiovascular and kidney outcomes in elderly persons without chronic kidney disease. Ann Intern Med 2006;145:237246. 